The Conquest of the Stratosphere

By Chas. G. Philp. Pp. ix + 205. (London : Sir Isaac Pitman and Sons, Ltd., 1937.) 7s. 6d. net.

NR. PHILP'S two books are of very different 1 value; their defects are alike, their merits dissimilar. Both are marred by a superficial and far from accurate handling of scientific facts and hypotheses, and both suffer from that adjectival rash which infests so many works of popular science"hazardous risks", "intrepid explorers", "unknown regions", "entrancing story", "astounding information", "tremendous height" and so on. As for "evaporizing", "stratonaut", "astronautist"-—what words!

The merits of "Stratosphere and Rocket Flight", which was published some time ago, lie in its exaggerations, its failure to present a fairly balanced picture of the great practical difficulties that must be overcome before the great theoretical possibilities of reaction propulsion are converted into directed achievement. They are merits, because they are sufficiently obvious to a reader of the most modest intelligence, and because they will compel the reader to think and question at every page. "The Conquest of the Stratosphere" opens inauspiciously with a chapter in which our incomplete knowledge of the atmosphere is presented in obsolete and misleading form. Scientific facts and the scientific results of stratospheric flight are not presented in a form which will convince the average reader that justification of the pains is yet in sight.

But a clear majority of the pages are devoted to vivid and straightforward description of each of the historic manned balloon flights into the stratosphere, from Glaisher and Coxwell in 1862 to Stevens and Anderson in 1935. The stories, which are mainly based on a close (sometimes too close) following of the actual logs, are absorbingly interesting, and the modest price of the book is handsomely earned in this connected narrative of exploration. It can be most cordially commended to everyone who needs reassurance that grandeur can still in the twentieth century be attained in communal organization and in individual courage, freed from passion and selfinterest. For those not yet tormented by philosophic doubts and fears, it is a fine story book.

\section{Insects of the British Woodlands}

By Dr. R. Neil Chrystal. Pp. xiii $+338+33$ plates. (London and New York: Frederick Warne and Co., Ltd., 1937.) 7s. $6 d$. net.

7 HIS book is intended primarily for those who are concerned with the management of British forests and woodlands. Through the operation of the Forestry Commission, extensive tracts of land have been taken over in Britain for planting with forest trees. These trees include both native and alien species and, as the work goes forward, increasing attention will be directed to their various insect enemies. There has been a very evident need for a good practical manual on the insect enemies of the forester and, in fact, of trees in general. Such a work requires to be up to date and treat of the insect concerned in close connexion with methods of forestry practice.
This want may be regarded as being adequately met by the present book. Those who use it will find sufficient introductory matter to become acquainted with the essential features of insect biology and structure. They will also be able to name, without undue difficulty, the more important insects encountered and, at the same time, gain an insight into their habits and relation to forestry. The various conditions and circumstances which govern insect outbreaks in woodlands are explained : both natural enemies and artificial methods of repression are clearly discussed, while simple methods for the collection and study of insects are given.

Written by an author who has had much firsthand experience with the subject, the book provides the sort of information that is required. It is not overburdened with technicalities, and the clear, straightforward style in which it is written should commend it also to the notice of nature study teachers and others interested in insect life. It is well and fully illustrated and very reasonably priced.

A. D. I.

Sound-Recording for Films :

a Review of Modern Methods. By W. F. Elliott. Pp. $x i+134+12$ plates. (London: Sir Isaac Pitman and Sons, Ltd., 1937.) 10s. 6d. net.

$7 \mathrm{HE}$ accuracy of aim, clarity of conception, and exactness of expression which characterize $\mathrm{Mr}$. Elliott's work are well illustrated in its title. His book is not one on "Sound Recording on Film", with detailed description of the physics and chemistry of the sound track and the related apparatus. It is a shrewd and stimulating discussion of the art of that highly skilled, imaginative, ingenious, agile and patient collaborator in film-making who bears the regrettable though comprehensible title of "recordist". $A$ very few inexactitudes and obscurities in the brief references to acoustic physics are quite unimportant in a book full of wisdom, common sense and sound artistic judgment.

Although it is designed as a practical guide to the technician, the book is of a much wider interest. Its claim to be the first of its kind is justified, and it should be read not only by every recordist but also by every director. The general reader will find it enthralling and illuminating. He will get a fair impression of one aspect of that almost incredibly onerous labour, that meticulous care, and that more than humanly patient iteration which goes to the making of a good film, and of which direct evidence must be completely absent from the good film.

Nearly everything that Mr. Elliott says is so right that there is a temptation to call it obvious. A visit to an average film show will cure the temptation, and will renew the feeling that such a visit must be a somewhat painful experience for Mr. Elliott and for any recordist of his high quality and ideals.

A word must be said for the ingenious "postsynchronization" of the dust-cover, which shows on the front a typical film scene and on the back the battery of technical aids which stands-in this case literally-behind the scene. 